\title{
A Novel Way for Propagation of Huperzia squarrosa (G. Forst.) Trev.
}

\author{
Sanatombi Devi YUMKHAM*, Potsangbam Kumar SINGH \\ Centre of Advance Study in Life Sciences, Manipur University, Ethnobotany and Plant Physiology Laboratory, \\ Canchipur-795003, India; rifle_yumkham@rediffmail.com; potsangbamk031@gmail.com
}

\begin{abstract}
Huperzia squarrosa (G. Forst.) Trev. is an endangered epiphytic fern ally with economical, traditional and horticultural interest. It posses various alkaloids like huperzine, huperzinine, lycoporine and carina-tumine which are responsible for its medicinal property, and used in treating a wide range of aliments like general weakness, fever due to swelling, brain disorders, Alzheimer and Parkinson diseases. Over the years, it is experiencing rapid decline due to over-harvesting and loss of natural habitats. In order to check the problem and meet increasing demand with year round availability in local markets, a research programme was instituted to develop a suitable propagation protocol that can easily be understood by local growers. Two experimental models A and B (control) and corresponding media (I, II) were formulated separately to study enhancement of artificial bulbils in mature sporophytic tassel ferns ( $>5$ years). In Model A, conventional earthen pots $(30 \times 25 \mathrm{~cm})$ and Media I were used. Model B was set up using coconut shells filled with Media II. After 6-8 months, bulbils developed in Model A showed efficient viability rate (100\%), while bulbils failed to develop in Model B. The study highlights that this rare fern ally can be propagated easily through this novel way, being user friendly and affordable.
\end{abstract}

Keywords: bulbils, Manipur, Model A, Model B, propagation

\section{Introduction}

Among the lycopods, Huperzia squarrosa (G. Forst.) Trev. is one of the most beautifully allied fern species. It is an all-time favourite, among plant enthusiasts, due to its graceful foliage make-up, making stunning specimen hanging in lawns, gardens, arboretums, corridors, verandas, glass houses, etc. Naturally, it grows as epiphyte in dense moist forest at altitudes ranging from 1000 to 3000 meters and sometimes adapted as lithophytes or terrestrials. Many species, like Huperzia phlegmaria (L.) Rothm., $H$. serrata (Thunb. ex Murray) Trevis, H. phyllantha (Hook. and Arn.) Holub. etc. have recently earned a unique place as a potential medicinal herb, being used for several brain diseases' treatment, like Alzheimer, Parkinson, contusions, strains, swellings, schizophrenia and myasthenia gravis (Chang and But, 1987; College, 1985; Ma, 1997; Sun et al., 1999). Alkaloids from these plants, such as Huperzine A (Hup A), Huperzine B (Hup B), N-methyl-huperzine B, Huperzinine, Lycoporine A, Carina-tumine A etc. today have high demands in global markets by various pharmaceutical companies. To meet the demands, plants are extracted from wild, as there is no suitable propagation protocol that can easily be understood by common plant growers.

In Manipur (North Eastern India), H. squarrosa is an indispensable plant, having traditional, economical and horticultural significance. Stems are used in various religious ceremonies, and integrated as decorative stuffs in cane and bamboo related handicraft works (Yumkham and Singh, 2011). Active trading is carried on large scale mainly by womenfolk in local markets. The only means to meet daily supply of plant resource is directly from the forest. No propagation and harvesting techniques have ever been studied, nor developed for commercial purposes.

In Huperzia, reproduction takes place both by sexual and asexual means. Spores are sexual propagules, but they are usually inactive, complicated and germination takes years. For these plant groups, vegetative propagation using stem, leaf, root, rhizomes or other cuttings is a better option. It is also the most important method for many commercial horticultural plants (Hartmann et al., 1990). If propagation protocols for commercial production are not developed today, then people would use and exploit again the forest resources. This has become a threatening practice for decades and resulted in depletion of Huperzia mainly in valley forests of the state. Under the Department of Science and Technology (New Delhi), a research program was thus initiated to develop a cost effective, suitable propagation technique that is user friendly from common men's point of view.

\section{Materials and methods}

The present study was conducted during March 2009 - April 2012 in Manipur. Macroscopic and microscopic characters were studied from live specimen collected from Shirui Hill Range, Ukhrul District (Manipur), India and deposited in Manipur University Museum of Plant, MUMPS. 
28

\section{Study site}

The state Manipur is located in the extreme eastern part of India. With a total geographical area of 22,327 $\mathrm{km}^{2}$, lying at latitude of $23^{\circ} 83^{\prime} \mathrm{N}-25^{\circ} 68^{\prime} \mathrm{N}$ and longitude of $93^{\circ} 03^{\prime} \mathrm{E}-94^{\circ} 78^{\prime} \mathrm{E}$, it falls under Indo- Myanmar hotspot regions of the world (Meyers et al., 2000). Topographically, the whole state is divided into central valley $\left(1,843 \mathrm{~km}^{2}\right)$ and outer hilly region. Hills cover $9 / 10$ of the total state area and today Huperzia squarrosa are naturally growing on hills only.

\section{Plant materials and media}

Mature sporophytic tassel ferns, not younger than five years, were bought from private ferneries. Two types of natural media were used for propagation, (a) Media I - sand, mud, Cyatheae dead wood and dried Azolla in 1:2:1:1 (b) Media II-Cyatheae dead wood, sand and dried Azolla in 2:1:1 ratio. All the media were formulated based on the ease of resources' availability, cost effectiveness keeping in view the general interest of womenfolk, who are predominantly involved in tassel growing and related trades. Media were sundried for 7 days, weeded and sterilized later with hot water $\left(\sim 60^{\circ} \mathrm{C}\right)$. Easily available surface disinfectants (isopropyl alcohol and fungicide benlate) were used, especially during detachment of bulbils from mother plants, to reduce infection. Watering frequency was regulated during summer and winter days. Natural day length, during

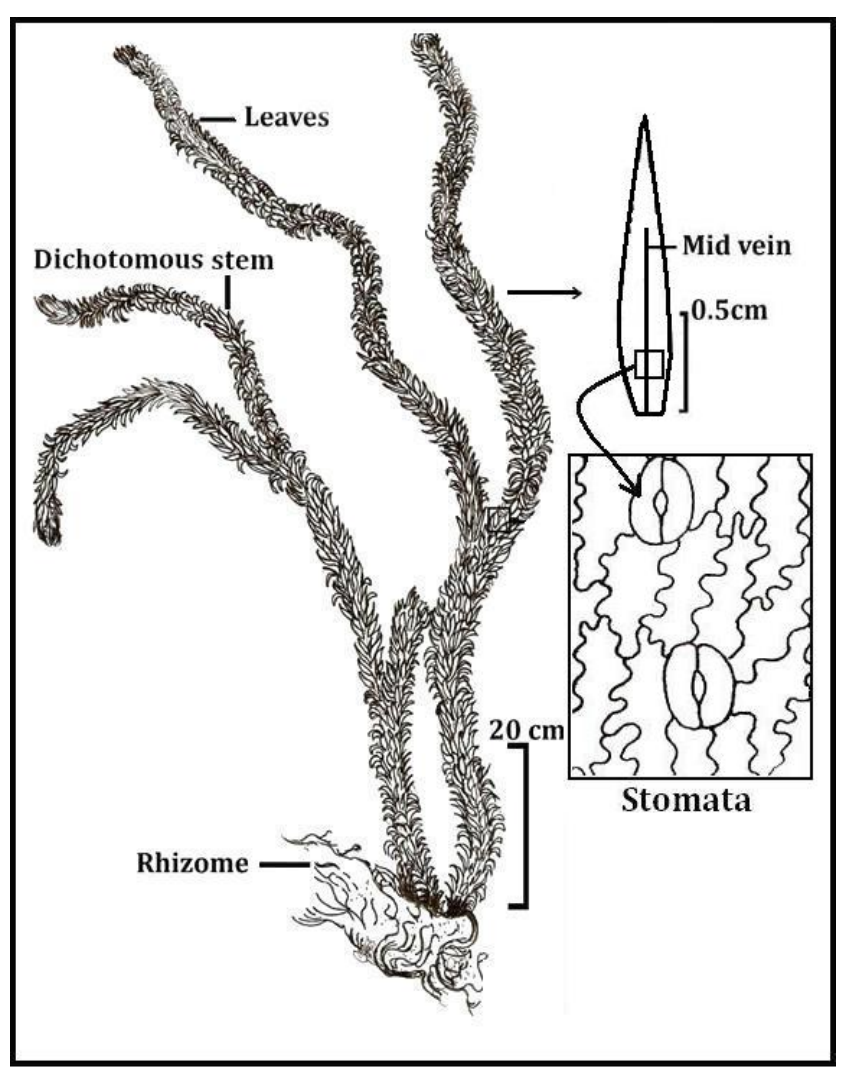

Fig. 1. Diagrammatic representation of a mature tassel fern the course of experiment, was $10 \pm 2$ hours. The whole experiment was conducted in shade with low light intensity.

\section{Results}

\section{Model A}

Ten tassel mother plants ( $>5$ years) were planted in earthen pots $(30 \times 25 \mathrm{~cm})$ filled with Media I. For plantation in pots, drainage facility is important and therefore pots, with two holes $(1.5 \mathrm{~cm}$ diameter) on bottom, were selected to check water logging. Care was taken while filling rooting media by covering the holes with broken pieces of earthen pot or charcoal blocks.

Frequency of watering was manipulated based on the season and humidity. During summer, plants were watered once a day and in cold winter days, watering was restricted to every alternate day. Liquid fertilizers, like fish and meat extracts, were given once a week. Care was taken not to overflow the whole pot. This will check wash out nutrients flow, over saturation of media and infestation from unwanted microorganisms. The pots were seated in wooden racks ( 2 meters high) inside green houses or in shade. After 6-8 months, apical stems become greener than the rest and begin to turn upwards making a $U$ turn against the gravity. When it attains a length of $5-8 \mathrm{~cm}$, aerial propagating roots (2-4 in numbers) developed at the juncture of U-spot. These are called bulbils and are the replica of the mother plant. Sometimes, bulbils detach itselfs from mother plant or removed physically with sharp sterilized blades. It was then immediately planted in sampling pots $(9 \times 10 \mathrm{~cm})$ filled with sterilized rooting media (Fig. 2 and 4).

\section{Model B}

Coconut shells with fibers were carefully stitch together at many points with strong non-rusted binding wires in such a manner that the terminal basal portion forms a cone without any apparent holes and the upper apical mouth opens wide enough to insert a mature tassel fern inside. The number of shells depended on the size of rhizomatous plant to be inserted. Usually 8-12 shells extracted from two mature coconuts is sufficient for planting a mature tassel fern. The model was submerged and soaked in water for 24 hours. About $1 / 3^{\text {rd }}$ of the model was filled with Media II and a mature tassel fern was inserted carefully and eventually filling the rest of empty space with the same media. It was hanged on bars at height within reach or over branches in shady areas. As the fibers and media are porous, care was taken while watering as it easily drained down. Watering frequency was regulated in manner as follows, (a) summer- 4 times a day in 4 hour intervals (b) Winter- 2 times a day with 6 hour intervals. Natural liquid fertilizers were supplied three times a week to supplement loss of drained nutrients from watering. Bulbils failed to develop even after 24 months of observation (Fig. 3 and 5). 


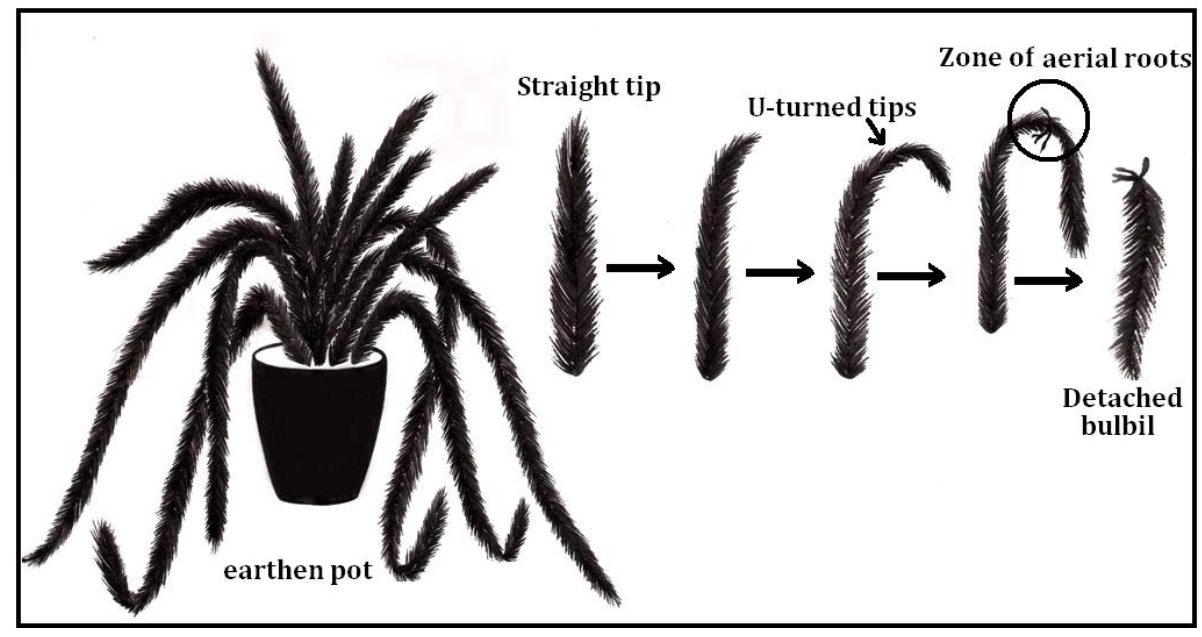

Fig. 2. Diagrammatic representation of Model A

\section{Discussion}

Geologically and phylogenitically, tassels, a key Lycophyte, are the oldest living vascular plants with specialized architectural back up. Unique body structure includes overlapping sporangia to form cones at the end of branches and simplicity in foliage morphology, but with equal ancient novelties (Benzing, 2012). Huperzia are slow growers, their vital growing parameters include relative humidity (78\%), soil water content (10-30\%), soil $\mathrm{pH} 4.57-5.31$ and organic matter (6.18-9.75\%). Germination of a spore could take 7 or more years to develop into a gametophyte (Cobb, 1963). This is one of the key factors for rapid decline of their population, rate of habitat exploitation being increased over the years; while on the other hand, the biological life cycle from sporophyte to gametophyte is rather a lengthy process. The situation is catapulted again in the absence of propagation protocol suitable to the land and people. With more research in Huperzine drugs and allied derivatives for curing various mental diseases, the market demand in global context has also increased. Hence, production of tassel ferns on large scale for commercial purpose is yet a challenging task.
As most ferns species, tassel ferns also produce bulbils. These are miniature aerial propagating propagules produced along axils of stem, leaves or bracts. Mature bulbils, when grown in full size, will eventually fall off the mother plant by detaching themselves to the ground (Gola, 2008). In Huperzia squarrosa, rhizomes adhere to host trees for support. These rhizomes are not true roots and regarded as an extension of stem performing the function of roots. They form matted dense network around substrate and specialized in trapping water rich in nutrients. This network further enhances effective aeration and retains plant moisture. As bulbils are reflections of adaptation to specific environmental conditions, their formation can also be enhanced artificially. In the present study, the formulated models A and B enacted similar conditions to test the production of bulbils from apex microphyllous leafy positions.

In Model A, there is restricted supply of water with poor aeration in the rhizomatous region due to a higher percentage of mud within the non porous wall of earthen pots. This condition enhances a unique adaptation to replicate itself by producing bulbils. Plantlets from bulbils show high survival rate (100\%). As many as 7-10 bulbils

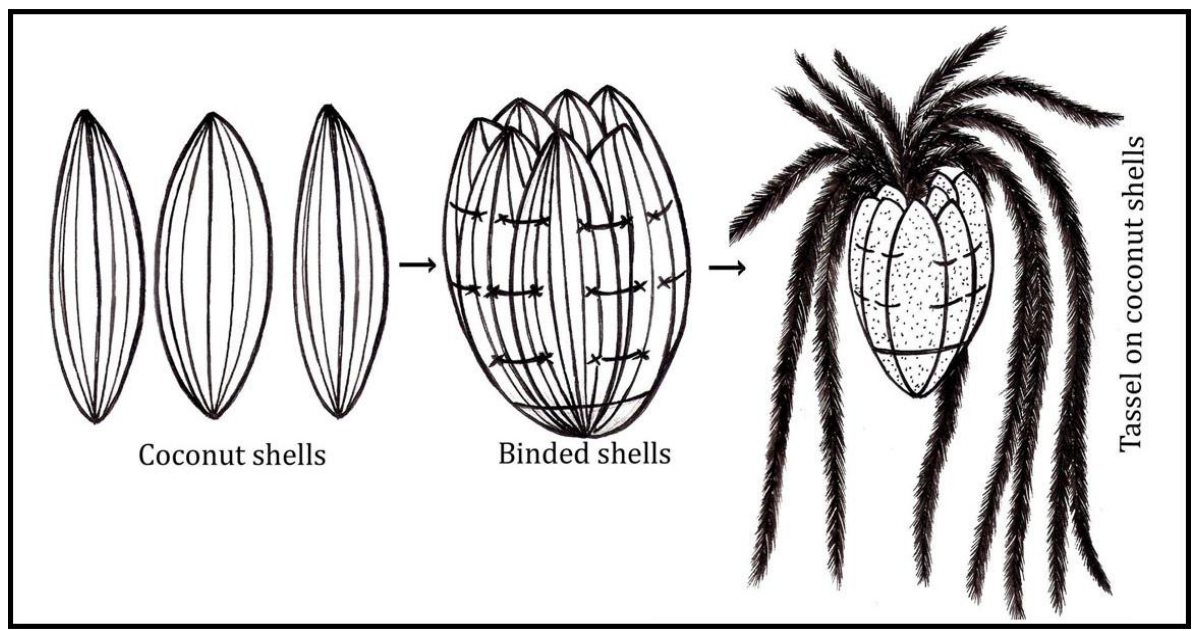

Fig. 3. Diagrammatic representation of Model B growing in coconut shells 


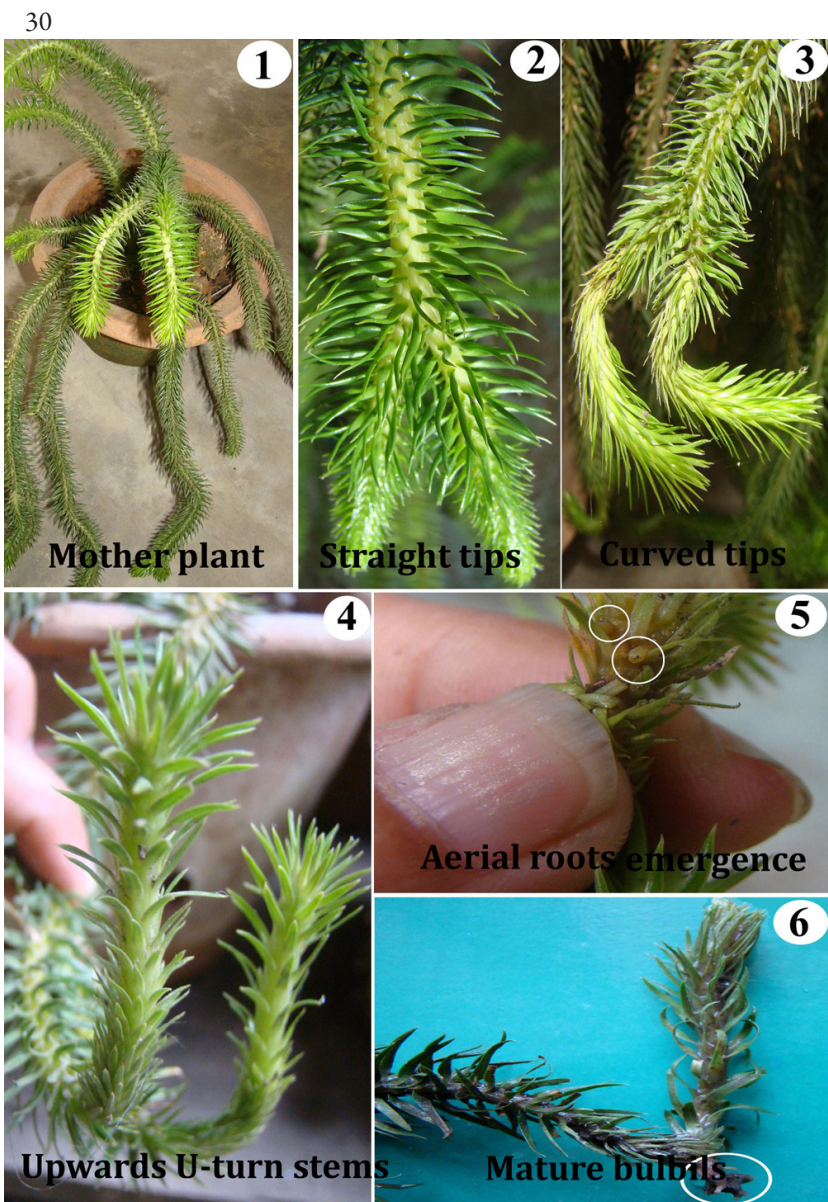

Fig. 4(1-6). Stages of bulbils development

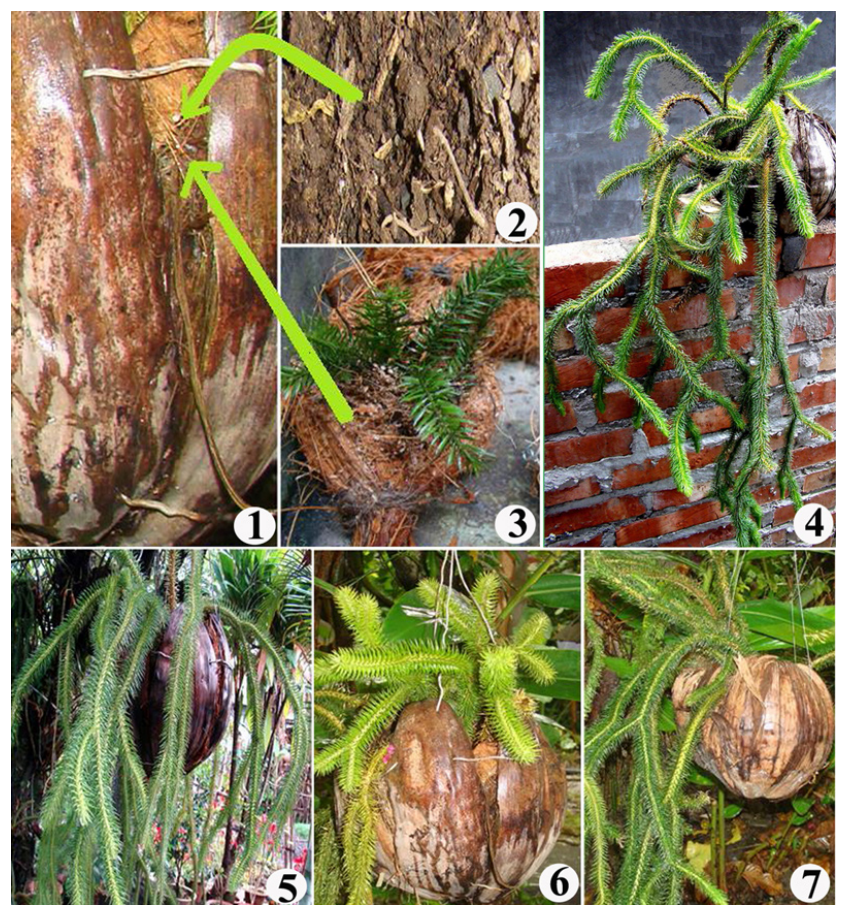

Fig. 5(1-7). Tassel propagation in coconut shells

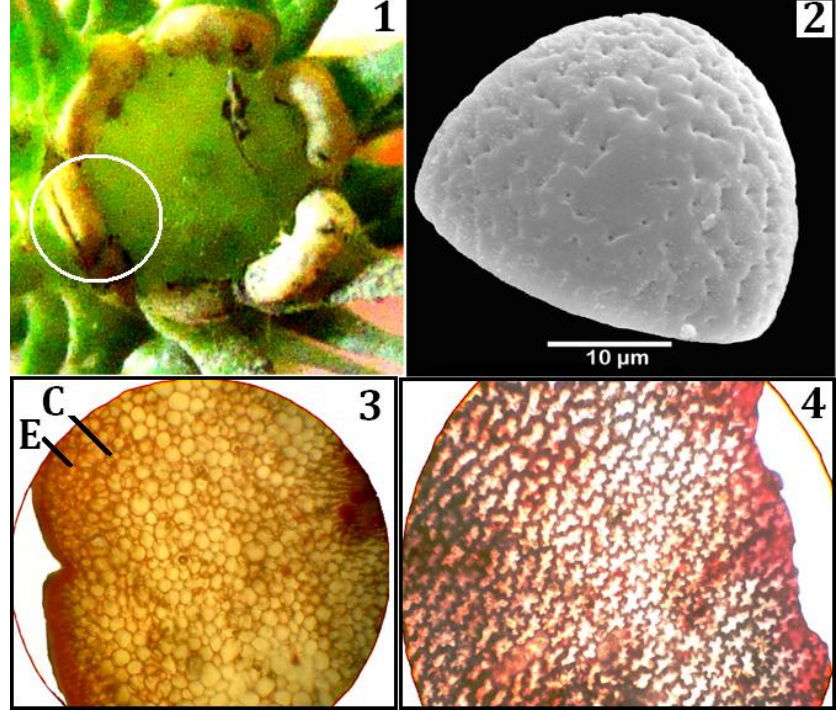

Fig. 6 (1-4). Macroscopic and microscopic characters in $H$. squarrosa: (1) Sporangium dehiscence (2) Spore with pits (3) Transverse section of stem showing epidermis, E and cortex, C (4) Leaf section with anomocytic stomata

can be artificially enhanced, one at a time from a mother tassel fern of about 5 years. In natural habitat, bulbils touch host substrate slowly and when dislodged by gusts of wind or birds, they land comfortably in a suitable place and quickly grow into a full plant. In Model B, supply of water and nutrients is regularly monitored. As the coconut fiber wall is very porous, there is sufficient rhizome aeration and natural mobility on stem is maintained just as in natural habitat. Bulbils evidently failed to develop. Through this model, spores can be easily harvested economically if one intended to propagate from spores.

A peculiar feature seen in $H$. squarrosa that enhances successful propagation is attributed to its meticulously organized sporophytic body. Leaves are microphyllous arranging in whorls, which explains the xerophytic nature (Fig. 1). Sporophylls are loosely hanging down the branches to enable effective spore dispersal along with the movement of air and other biological agents. Dehiscence takes place by transverse slit and spores are small in size $(29 \times 30 \mu \mathrm{m})$, so that it can easily lodge in any suitable substrate (Fig. 6.1 and 6.2). The whorl leaves at basal rhizome region are arranged between $30^{\circ}-50^{\circ}$, so that it can trap falling debris, dirt and rainfall. Stem is thick and very succulent which helps plant to survive in extreme xeric conditions. Anatomically, epidermal cells are superficial, thickly cutinized with anticlinal walls and broad sclerenchymatous cortex, which is an adaptation usually seen in xerophytes and lithophytes. Stomata anomocytic without subsidiary cells, amphistomatic but sparsely distributed, which reduces rate of transpiration (Fig. 6.3 and 6.4).

From the above discussion, it was seen that $H$. squarrosa can be successfully propagated through Model A if we want bulbils for multiplication, and Model B to harvest quality spores for various medicinal, palynological 
and horticultural purposes. It is so far the most suitable inexpensive novel and easy propagation method for local traders. With further research in hormone applicability for large scale production, this propagation protocol can further be used in regeneration of their natural population in the wild.

\section{Acknowledgements}

Authors are grateful to Department of Science \& Technology (DST), New Delhi, India under SEED Division and Agharkar Research Institute (ARI), Pune (Grant No. SSD/ SS/ 012/ 2009) for financial support.

\section{References}

Benzing DH (2012). Air Plants: Epiphytes and Aerial Gardens. Cornell University Press.

Chang HM, But PPH (1987). Pharmacology and applications of chinese materia medica. World Scientific, Singapore.

Cobb B (1963). A field guide to ferns and their related families. Houghton Mifflin Company.

College JNM (1985). The Dictionary of Traditional Chinese Medicine. Shanghai Sci-Tech Press, Shanghai.
Gola EM (2008). Reproductive strategies of Huperzia, 5-14 p. In: Szczesniak E, Gola E (Eds.). Club mosses, horsetails and ferns in Poland-resources and protection. Polish Botanical Society and Institute of Plant Biology, University of Wroclaw, Wroclaw.

Hartmann HT, Kester DE, Davies FT (1990). Plant Propagation Principles and Practices. $5^{\text {th }}$ Ed. Prentice Hall, Englewood Cliffs, NJ, New York, USA.

Ma XQ (1997). Chemical studies on natural resources of $\mathrm{Hu}$ perzia and its related genera in China. Chinese Academy of Sciences, Shanghai.

Meyers N, Mittermeier RA, Mittermeier CG, Fonseca GAB, Kent J (2000). Biodiversity hotspots for conservsation priorities. Nature 403:853-858.

Sun QQ, Xu SS, Pan JL (1999). Huperzine-A capsules enhance memory and learning performance in 34 pairs of matched adolescent students. Acta Pharmacol Sin 20:601-603.

Yumkham SD, Singh PK (2011). Huperzia squarrosa (G. Frost.) Trev. (Lycopodiaceae) in Manipur: Taxonomy and Biological Aspects. Taiwania 56(2):157-164. 